\title{
Aquaponic system development as an educational tourism destination in Sukowilangun Village, Malang Regency
}

\section{Pengembangan sistem akuaponik sebagai destinasi wisata edukasi di Desa Sukowilangun, Kabupaten Malang}

\author{
Sufiyanto Sufiyanto', Mochammad Musafaul Anam², Zaid Dzulkarnain Zubizaretta ${ }^{3}$ \\ ${ }^{1}$ Departemen Teknik Mesin, Fakultas Teknik, ${ }^{2}$ Departemen Perhotelan, Program Diploma Kepariwisataan, \\ ${ }^{3}$ Departemen Teknik Sipil, Fakultas Teknik, Universitas Merdeka Malang \\ Jl. Terusan Raya Dieng No.62-64 Malang, 65146, Malang, Indonesia
}

\begin{abstract}
ARTICLE INFO
\section{ABSTRACT}

Received: 2020-12-21

Revised: 2021-04-04

Accepted: 2021-08-17

The tourism sector has been targeted to be a tool that may develop people's economy. Kelompok Sadar Wisata (Pokdarwis) Sukowilangun Berseri is a community that develops Taman Suko at Sukowilangun, Kalipare, Malang Regency. However, the increasing number of tourism effect for the local community at Sukowilangun can still be categorized at a low-level. Besides, the management capabilities and resources of the local community in developing Taman Suko as a local tourist destination have not been able to attract more tourists. We carry out a community service program through diversifying

Keywords: our business with the implementation of an aquaponics system to increase income derived from tourism management, providing assistance in efforts to develop tourism potential, and empowering

Aquaponic system, Community empowerment, Education tourism destination local community-based communities at Taman Suko. The results of this program were implementing aquaponic system as a business diversification as well as an education theme for tourists on how freshwater fish and vegetables are bred, developing some tourism support facilities such as photo spot, pathways, and fish pond, and promoting local culinary business through social medias and a video profile.
\end{abstract}

(C)2021 Published by University of Merdeka Malang. This is an open access article distributed under the CC BY-SA 4.0 license (https://creativecommons.org/licenses/by-sa/4.0/)

How to cite: Sufiyanto, S., Anam, M. M., \& Zubizaretta, Z. D. (2021). Aquaponic system development as an educational tourism destination in Sukowilangun Village, Malang Regency. Abdimas: Jurnal Pengabdian Masyarakat Universitas Merdeka Malang, 6(4), 465-477. https://doi.org/10.26905/abdimas.v6i4.5190

\section{PENDAHULUAN}

Desa Sukowilangun termasuk dalam wilayah Kecamatan Kalipare, Kabupaten Malang. Desa ini terbagi menjadi empat dusun, yakni Kampung Baru, Tawang, Kopral, dan Sukorejo atau biasa disebut Rekesan. Sebelah utara Desa Sukowilangun berbatasan dengan Sungai Brantas, di sisi timur dan selatan berbatasan dengan Desa Kalipare, sedangkan sisi barat berbatasan dengan Desa Arjowilangun. Mata pencaharian mayoritas penduduk di Sukowilangun adalah sebagai petani perkebunan, nelayan, dan 
ABDIMAS: Jurnal Pengabdian Masyarakat Universitas Merdeka Malang Volume 6, No. 4, November 2021: 465-477

tidak sedikit pemuda pemudi yang bekerja sebagai TKI dan TKW di luar negeri. Sebagian masyarakat Desa Sukowilangun yang tinggal disekitar Bendungan Sutami memanfaatkan potensi perairan tersebut untuk budidaya ikan menggunakan karamba dengan rancangan konstruksi tertentu sehingga dapat dikendalikan mengikuti pola pasang surutnya air bendungan. Budidaya ikan karamba ini berpotensi mendatangkan keuntungan yang besar bagi perekonomian masyarakat Desa Sukowilangun.

Potensi Desa Sukowilangun tidak hanya dari sektor perkebunan, tapi juga dari sektor keindahan alamnya. Topografi Desa Sukowilangun yang terletak di dekat Sungai Brantas dan di daerah perbukitan memiliki potensi untuk pariwisata. Objek wisata yang sedang dikembangkan oleh masyarakat sekitar yaitu Taman Suko yang berada di pinggiran Sungai Brantas. Pengembangan wisata Taman Suko terus dilakukan oleh masyarakat setempat melalui komunitas Kelompok Sadar Wisata (Pokdarwis) Sukowilangun Berseri. Pengembangan destinasi wisata lokal tersebut diharapkan dapat mengangkat perekonomian masyarakat setempat.

Pemanfaatan keberadaan Taman Suko tidak hanya sebagai destinasi wisata lokal tetapi juga mengarah pada pengembangan potensi seni dan budaya masyarakat setempat. Beberapa kegiatan pementasan seni dan budaya seperti teater, kesenian jaranan, bantengan, tari, dan musik diadakan oleh warga sekitar di Taman Suko tersebut. Selain itu, acara-acara ritual keagamaan di Makam Eyang Suko, bersih desa, dan perayaan HUT RI 17 Agustus juga diselenggarakan di sana. Hal ini dimaksudkan untuk menjadikan Taman Suko sebagai sentra kegiatan masyarakat dan menyebarkan keberadaan Taman Suko sebagai icon destinasi wisata masyarakat Sukowilangun.

Pengelolaan dan pengembangan wisata Taman Suko dilakukan secara swadaya oleh Pokdarwis Sukowilangun Berseri. Upaya pengembangan yang dilakukan oleh masyarakat melalui pokdarwis relatif berjalan dengan baik, namun masih ada beberapa kendala dihadapi. Pertama, pendapatan anggota yang tergabung dalam pokdarwis dari pengelolaan wisata yang ada masih relatif rendah. Selama ini pendapatan yang diperoleh berasal dari penjualan tiket parkir dan kolam renang sebesar Rp. 5000,-/ orang. Dengan jumlah pengunjung yang masih terbatas, maka tingkat pendapatan yang diperoleh juga kecil. Tentunya hal ini akan berdampak pada rendahnya tingkat kesejahteraan bagi anggota pokdarwis dan juga minimnya anggaran untuk pengembangan serta pemeliharaan Taman Suko kedepannya. Kedua, perlunya pengelolaan potensi wisata dan pemberdayaan masyarakat agar keberlanjutan dalam pengembangan Taman Suko dapat tercapai. Kemampuan untuk mengembangkan potensi wisata dan sumber daya masyarakat yang ada diperlukan agar wisata Taman Suko bisa menjadi sebuah destinasi wisata yang semakin menarik dan dikenal masyarakat. Konsep pengembangan Taman Suko menjadi sebuah destinasi wisata tematik yang berbasis pada pemberdayaan masyarakat harus direncanakan secara berkelanjutan.

Konsep pemberdayaan masyarakat merupakan upaya pembangunan ekonomi yang berbasis pada nilai-nilai sosial masyarakat tersebut (Andrijono \& Sufiyanto, 2021; Cahyaningsih et al., 2021). Melalui pemberdayaan ini, masyarakat diharapkan memperoleh peluang untuk melakukan upaya produktif dengan cara memanfaatkan sumber-sumber daya di sekitarnya (Yuniarti et al., 2020). Terciptanya peluang dan prospek usaha yang mandiri dapat tumbuh melalui upaya-upaya pemberdayaan masyarakat (Torrido, 2013; Bancin, 2011). 


\section{Aquaponic system development as an educational tourism destination in Sukowilangun Village, Malang Regency Sufiyanto Sufiyanto, Mochammad Musafaul Anam, Zaid Dzulkarnain Zubizaretta}

Pengembangan sistem pertanian dan perikanan secara terpadu menjadi konsep yang banyak diterapkan oleh masyarakat di daerah dengan sumber air dan lahan yang terbatas (Budiyanto et al., 2019). Sistem akuaponik banyak diterapkan pada saat ini utamanya terkait dengan konsep urban farming bagi masyarakat perkotaan akibat keterbatasan lahan (Tutuko et al., 2018). Optimalisasi penggunaan sumber air yang terbatas dan perbaikan kualitas air merupakan keunggulan dari sistem akuaponik (Handayani, 2018). Sistem ini merupakan gabungan antara sistem budidaya ikan (akuakultur) dengan sistem bercocok tanam tanpa menggunakan tanah (hidroponik).

Penerapan sistem akuaponik mempunyai keuntungan dapat memperbaiki kualitas air kolam yang mengandung kotoran ikan dan dapat memanfaatkan sisa limbah pakan ikan (Prayogo, 2019; Sitanggang, 2019; Zidni et al., 2019). Air yang berasal dari kolam ikan dimanfaatkan untuk menyiram tanaman sayuran sekaligus sebagai pupuk organik bagi tanaman (Halim \& Pratamaningtyas, 2020; Budiyanto et al., 2019). Hal ini disebabkan karena air kolam mengandung unsur hara yang berasal dari kotoran ikan tersebut. Kotoran ikan diurai oleh mikroba yang ada dalam kolam menghasilkan unsur hara yang dibutuhkan oleh tanaman sebagai pupuk organik. Selanjutnya tanaman memfilter air dan air kembali mengalir ke dalam kolam.

Sistem akuaponik memiliki beberapa hal yang menjadi keuntungan dan kekurangan dalam implementasinya (Sant, 2017). Keuntungan sistem akuaponik antara lain: (1) Dapat menghasilkan produk ikan dan sayuran secara bersama-sama; (2) Mampu diimplementasikan di lahan yang sempit; (3) Hasil produk ikan dan sayuran tersebut bersifat organik; dan (4) Lebih hemat dalam pemanfaatan air. Disamping itu sistem akuaponik juga memiliki kekurangan diantaranya: (1) Sistem sirkulasi membutuhkan energi listrik untuk menggerakkan pompa air; (2) Memerlukan keahlian yang khusus dalam pengoperasiannya; dan (3) Biaya instalasi lebih mahal.

Jenis sayuran yang biasa ditanam dalam sistem akuaponik (Amida, 2020), antara lain seledri, sawi, kangkung, selada, bayam, tomat, dan cabai. Sayuran ini merupakan jenis-jenis yang biasa dikonsumsi oleh masyarakat dan relatif mudah untuk diterapkan pada sistem akuaponik. Sedangkan untuk jenis ikan air tawar yang biasa dibudidayakan terdiri dari: nila, gurami, lele, mujair, bawal, bahkan ikan hias.

Untuk lebih mengenalkan potensi wisata alam Taman Suko, pemanfaatan media sosial dan internet merupakan upaya penyebaran informasi dalam rangka promosi wisata (Anam, 2017). Melalui pemanfaatan teknologi informasi tersebut, pengelola wisata Taman Suko dapat melakukan promosi wisata secara online di media sosial Facebook, Instagram, Line, Youtube, dan lainnya. Video profil wisata dan update konten promosi wisata merupakan hal yang menunjang penyebaranluasan informasi serta jaringan promosi wisata (Sonalitha et al., 2019). Pendampingan dalam pengembangan potensi dan pemberdayaan masyarakat menjadi bagian penting dalam mewujudkan pengelolaan wisata yang mampu meningkatkan kesejahteraan masyarakat sekitarnya (Widayati et al., 2019). Kegiatan pengabdian masyarakat ini bertujuan untuk melakukan pendampingan kepada pengelola wisata Taman Suko sehingga mampu mengembangkan potensi wisata yang berbasis pada pemberdayaan masyarakat.

\section{METODE}

Pelaksanaan program pengabdian Unmer Membangun Desa (UMD) 2020 ini berlangsung selama 4 (empat) bulan, yaitu mulai September s/d Desember 2020. Langkah awal sebelum semua rancangan 
ABDIMAS: Jurnal Pengabdian Masyarakat Universitas Merdeka Malang Volume 6, No. 4, November 2021: 465-477

kegiatan/program dilaksanakan, tim pelaksana pengabdian dan mitra beserta anggota pokdarwis melakukan koordinasi tentang rancangan kegiatan dan anggaran, waktu pelaksanaan dan sumber daya yang dibutuhkan. Hal ini perlu dilakukan agar semua komponen yang terlibat memahami tujuan dan target pelaksanaan program pengabdian yang akan dilaksanakan. Mitra dalam kegiatan pengabdian UMD ini adalah Pokdarwis Sukowilangun Berseri yang beranggotakan 20 orang warga masyarakat setempat.

Mengacu pada permasalahan yang ada, metode pemecahan masalah yang dilakukan oleh tim pelaksana pengabdian bersama-sama dengan anggota pokdarwis. Pertama, diversifikasi usaha dengan budidaya ikan air tawar dan menanam sayuran menggunakan sistem akuaponik (Gambar 1) sebagai upaya peningkatan pendapatan dalam pengelolaan wisata Taman Suko bagi anggota pokdarwis. Teknologi akuaponik merupakan gabungan teknologi akuakultur dengan teknologi hidroponik dalam satu sistem. Tujuan penerapan sistem akuaponik adalah untuk mengoptimalkan penggunaan air utamanya di daerah dengan kondisi sumber air yang terbatas/minim. Dengan sistem akuaponik, mitra dapat mengembangkan budidaya ikan air tawar sekaligus bercocok tanam sayuran. Air dari kolam ikan yang mengandung unsur hara dari kotoran ikan dimanfaatkan untuk mengairi tanaman sayuran. Sisa pemanfaatan air pada sistem hidroponik sayuran dikembalikan ke kolam. Adapun tahapan yang dilakukan adalah: (1) Melakukan rekondisi kolam budidaya ikan yang sudah ada sebelumnya. Pada tahap ini dilakukan modifikasi kolam dengan penambahan bak penyaringan kotoran menjadi 3 tahap dari 2 tahap pada kondisi sebelumnya. Hal ini dilakukan agar mekanisme penyaringan kotoran bisa lebih maksimal pada saat jenis ikan yang dibudidayakan adalah ikan lele dengan jumlah kapasitas yang lebih banyak; (2) Membuat sistem hidroponik yang selanjutnya dikombinasikan dengan sistem akuakultur. Kombinasi sistem ini bertujuan untuk mengoptimalkan penggunaan air kolam yang disirkulasikan untuk mengairi dan memberikan unsur hara pada tanaman sayuran. Setelah melewati sistem hidroponik, air mengalir kembali ke kolam budidaya ikan dengan kualitas air yang lebih bersih karena unsur hara dari kotoran ikan telah dimanfaatkan oleh tanaman sayuran; (3) Mengimplementasikan sistem akuaponik untuk budidaya ikan dan sayuran. Jenis ikan yang dibudidayakan adalah ikan lele, sedangkan sayuran yang ditanam adalah kangkung. Dengan sistem akuaponik, kapasitas ikan yang dapat dibudidayakan dalam kolam lebih banyak karena kolam dilengkapi dengan 3 bak penyaringan kotoran ikan dan air kolam disirkulasikan.

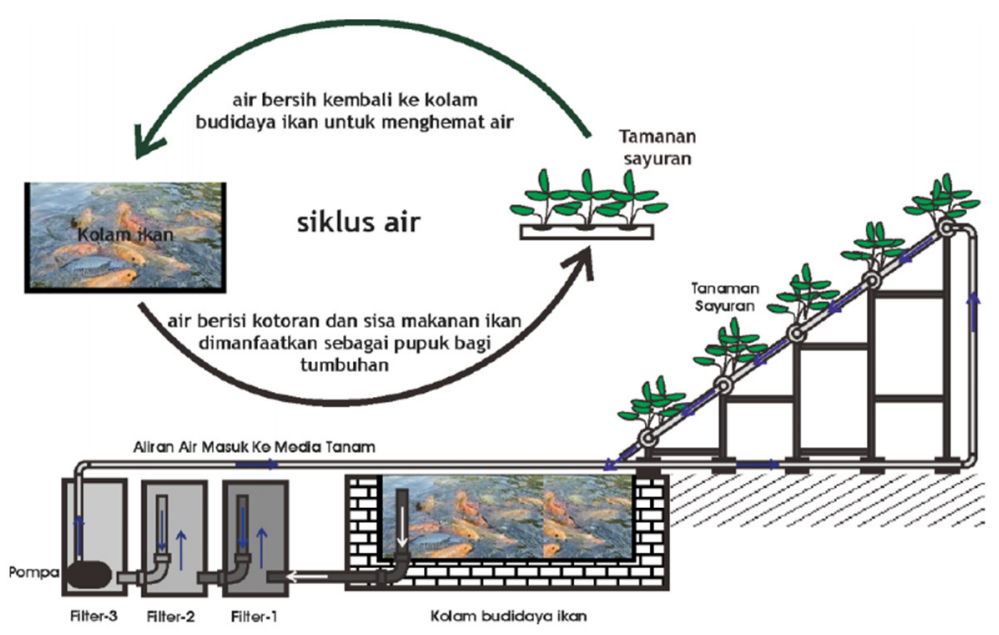

Gambar 1. Desain sistem akuaponik 
Kedua, pendampingan pengembangan potensi wisata Taman Suko dan pemberdayaan masyarakat yang berbasis komunitas. Tahapan yang dilakukan adalah: (1) Mengembangkan beberapa fasilitas penunjang di area wisata Taman Suko. Hal ini dilakukan agar fasilitas tersebut mampu memberikan daya tarik bagi pengunjung. Selama ini fasilitas wisata Taman Suko yang ada terbatas karena murni dirintis dan dikembangkan secara swadaya oleh mitra pokdarwis; (2) Memberikan pendampingan dalam membuat promosi kuliner yang mendukung wisata Taman Suko yang berbasis pada potensi dan sumber daya yang dimiliki oleh masyarakat Sukowilangun. Promosi kuliner ini dilakukan dengan membuat desain flyer promosi yang dapat diunggah di media online seperti Facebook dan Instagram. Diharapkan dengan pendampingan ini mitra dapat meningkatkan kesejahteraannya melalui sektor pariwisata yang dikelolanya; dan (3) Membuat video profil wisata Taman Suko dengan menambahkan tema edukasi tentang sistem akuaponik bagi pengunjung. Implementasi sistem akuaponik sekaligus menjadi percontohan bagi masyarakat Kelompok Wanita Tani (KWT) dan ibu-ibu PKK yang ada di Desa Sukowilangun untuk mendorong program ketahanan pangan di skala rumah tangga.

\section{HASIL DAN PEMBAHASAN}

\section{Hasil pelaksanaan program}

\section{Implementasi sistem akuaponik}

Kolam untuk budidaya ikan air tawar telah terealisasi dari program Kuliah Kerja Nyata (KKN) mahasiswa Unmer Malang pada semester ganjil 2019/2020 dan telah dimanfaatkan untuk pengembangan sistem akuakultur. Selanjutnya pada pelaksanaan program UMD ini, melengkapi sistem akuakultur yang ada dengan sistem hidroponik untuk menanam sayuran. Gabungan kedua sistem secara bersama menghasilkan sistem akuaponik.
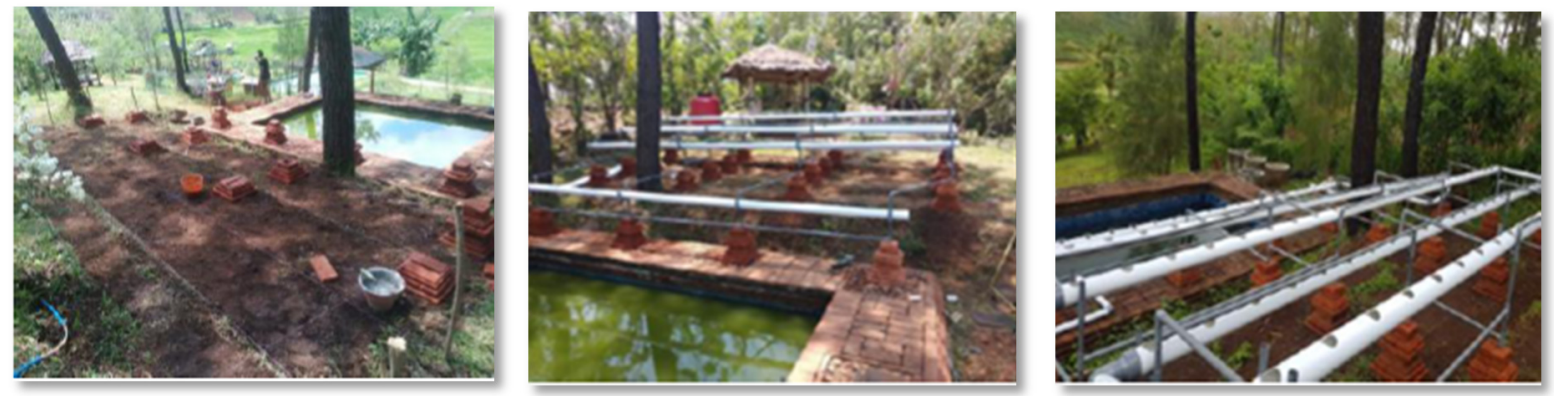

Gambar 2. Pembuatan sistem hidroponik

Sistem hidroponik (Gambar 2) dibuat menggunakan pipa PVC 3 dim dengan panjang 6 meter sebanyak 5 baris tiap lajur. Posisi instalasi pipa untuk sistem hidroponik dibuat dengan kemiringan sekitar 20 derajat agar sirkulasi air dengan gravitasi kembali ke kolam. Setiap lajur pipa PVC dibuat lubang untuk tempat media tanam sebanyak 25 lubang tiap lajur. Media tanam menggunakan wadah gelas plastik 200 cc diisi dengan serabut kelapa dan arang kayu. Jenis sayuran yang ditanam adalah kangkung, dimana setiap lubang tanam diberi 2 biji benih kangkung. Untuk teknis penggunaan kolam sistem akuakultur, 
ABDIMAS: Jurnal Pengabdian Masyarakat Universitas Merdeka Malang Volume 6, No. 4, November 2021: 465-477

diperlukan penggantian air kolam karena sebelumnya dimanfaatkan untuk budidaya ikan nila. Setelah dikuras dan diganti airnya, kolam perlu dikondisikan sebelum ditaburkan benih atau bibit ikan agar kondisi air stabil dan telah tumbuh mikroba serta lumut. Tahap pengkondisian air kolam ini memerlukan waktu \pm 4-5 hari. Selanjutnya, bibit ikan yang dibudidayakan adalah ikan lele. Bibit yang dimasukkan ke kolam sebanyak $18 \mathrm{~kg}$ dengan umur 1 bulan, dimana dalam $1 \mathrm{~kg}$ berisi 65 ekor (Gambar 3).
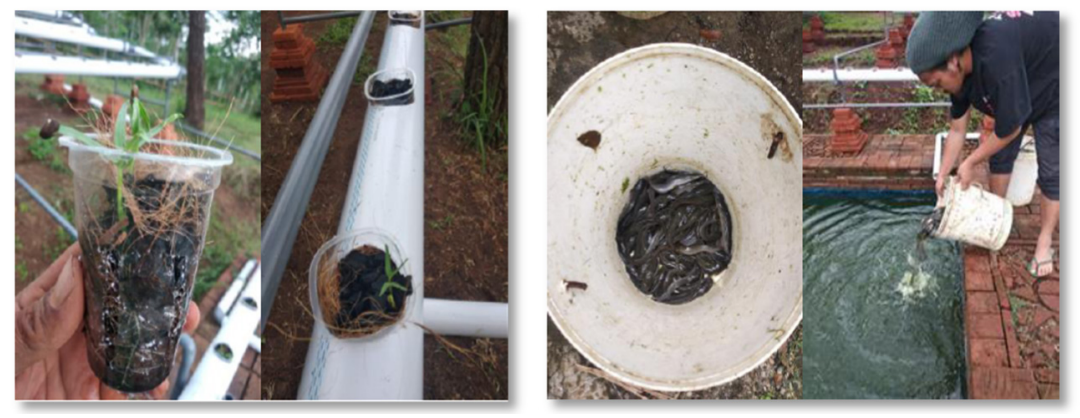

Gambar 3. Pembibitan sayuran kangkung dan penebaran bibit ikan lele

Setelah sistem akuakultur dan hidroponik berjalan secara bersamaan, maka sirkulasi air kolam dialirkan ke sistem hidroponik kemudian masuk kembali alirannya ke sistem akuakultur. Kombinasi sistem seperti ini menghasilkan sistem akuaponik. Untuk budidaya ikan lele, proses yang dilakukan disini adalah pembesaran ikan lele selama kurun waktu 8 minggu (2 bulan). Selama kurun waktu tersebut, sayuran kangkung bisa panen sebanyak 4 kali. Panen pertama sayuran kangkung memerlukan waktu \pm 2 minggu dari waktu penanaman bibit sayuran tersebut (Gambar 4). Selama proses perkembangan sayuran kangkung ini tidak memerlukan pupuk karena unsur hara yang berasal dari air kolam budidaya ikan dimanfaatkan oleh sistem hidroponik ini.
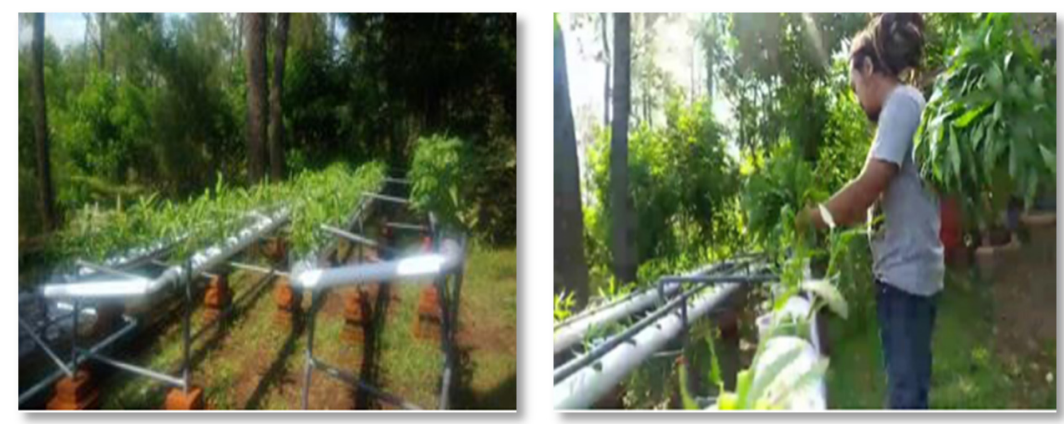

Gambar 4. Panen pertama sayuran kangkung sistem akuaponik

\section{Pendampingan pengembangan potensi wisata Taman Suko}

Tahap awal yang dilakukan dalam program pendampingan ini yang dilakukan adalah menambahkan beberapa fasilitas penunjang di area wisata Taman Suko. Beberapa fasilitas yang sudah ada antara lain, 
kolam renang anak, kandang kelinci dan merpati, serta beberapa gazebo. Pengembangan fasilitas penunjang wisata yang dilakukan dalam kegiatan ini adalah: (1) Jalan setapak berbahan batu bata sepanjang 26 meter dengan lebar 1 meter; (2) Melengkapi papan tempat duduk di 2 gazebo yang sudah ada; dan (3) Membuat 1 buah fasilitas swafoto berbentuk rumah kurcaci.

Jalur setapak yang dibuat ini merupakan jalur yang menghubungkan satu lokasi ke lokasi lainnya di area taman (Gambar 5). Selain itu, juga bertujuan secara khusus agar pengunjung tidak menginjak rumput atau tanaman yang ada. Disamping itu, memberikan kenyamanan bagi pengunjung saat musim hujan agar terhindar dari lumpur dan licin. Desain jalur setapak yang dibuat dengan model hiasan di pinggiran tepinya agar terlihat menarik.

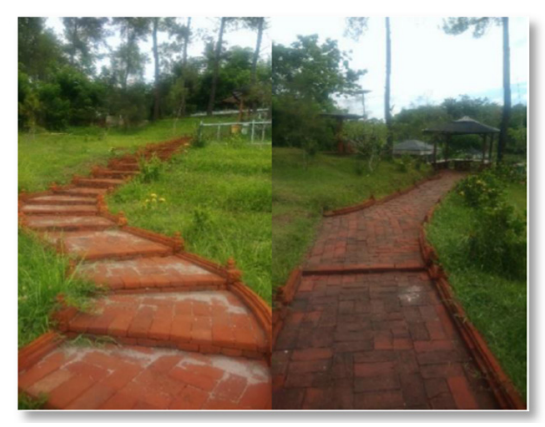

Gambar 5. Pengembangan jalur setapak di area Taman Suko

Fasilitas papan tempat duduk di beberapa gazebo yang ada belum tersedia. Sehingga penambahan fasilitas tersebut sangat dibutuhkan bagi pengunjung wisata sebagai tempat berteduh sambil menikmati pemandangan alam di Taman Suko. Terdapat 2 gazebo yang ditambahkan fasilitas papan tempat duduk (Gambar 6). Spesifikasi fasilitas tempat duduk tersebut terbuat dari papan kayu dengan ditumpu pondasi/umpak dari batu bata. Selain itu penambahan fasilitas swafoto di Taman Suko bertujuan agar pengunjung wisata mempunyai tema unik pada dokumentasi pribadi. Tema fasilitas swafoto yang dibuat berbentuk rumah kurcaci dengan ukuran luas $2 \mathrm{~m} \times 2 \mathrm{~m}$ (Gambar 7).
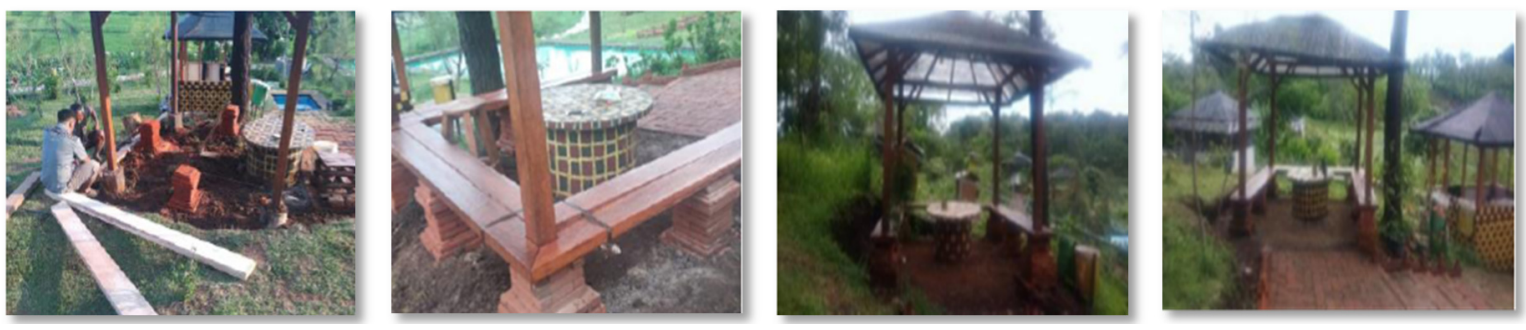

Gambar 6. Fasilitas tempat duduk di gazebo 
ABDIMAS: Jurnal Pengabdian Masyarakat Universitas Merdeka Malang Volume 6, No. 4, November 2021: 465-477
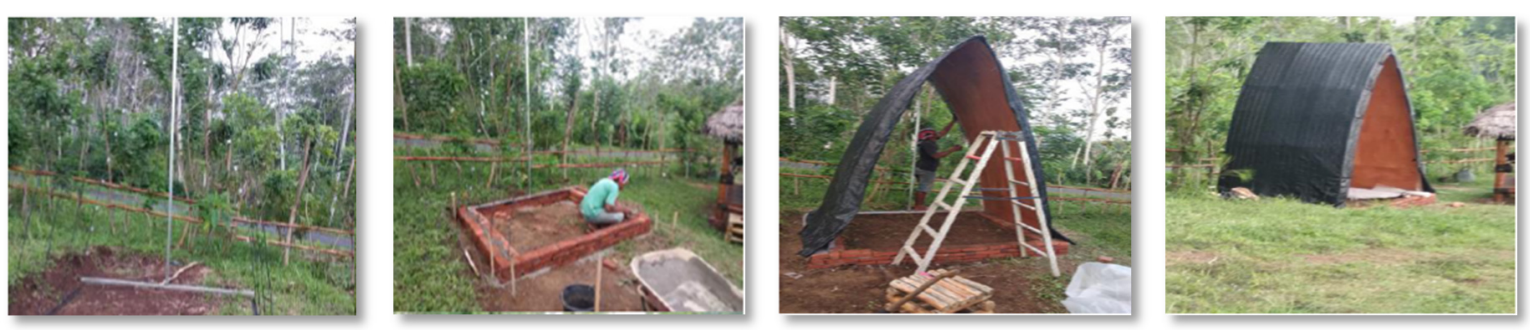

Gambar 7. Fasilitas swafoto tema rumah kurcaci

Untuk melengkapi wisata Taman Suko dengan tema edukasi, dibuat poster edukasi yang ditempatkan di pinggir kolam budidaya ikan. Poster tersebut berisi skema dan edukasi sistem akuaponik (Gambar 8). Fasilitas ini bertujuan memberikan tema wisata edukasi bagi masyarakat tentang sistem akuaponik dalam menunjang budidaya ikan air tawar dan bertanam sayuran secara bersamaan. Dengan sistem akuaponik ini, memberikan edukasi pemanfaatan atau keuntungan dalam mengoptimalkan penggunaan air utamanya di daerah dengan kondisi sumber air yang terbatas/minim. Selain itu, implementasi sistem akuaponik sekaligus menjadi percontohan bagi masyarakat Kelompok Wanita Tani (KWT) dan ibu-ibu PKK yang ada di Desa Sukowilangun untuk mendorong program ketahanan pangan di skala rumah tangga.
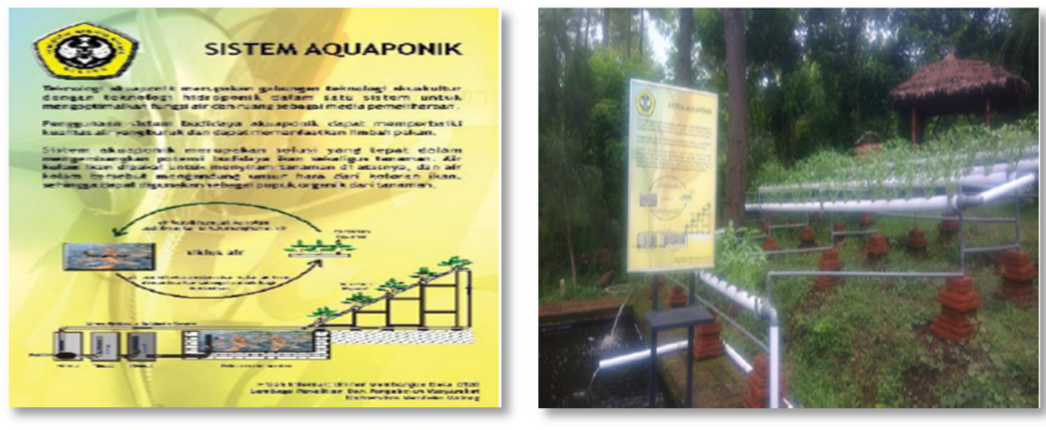

Gambar 8. Poster edukasi sistem akuaponik

Fasilitas penunjang lainnya sebuah wisata adalah kuliner. Anggota pokdarwis membuat wirausaha kuliner dengan membuka warung-warung yang berada di pinggir jalan sekitar Taman Suko. Ada 5 warung yang menyediakan kuliner bagi pengunjung dengan menu yang berbeda-beda. Warungwarung ini juga menjual produk-produk olahan makanan ringan produksi warga setempat, bahkan ada yang membuat kue brownies berbahan dasar tepung Mokaf. Tepung mokaf adalah tepung yang dibuat dari ketela pohon yang banyak dihasilkan di daerah sekitar. Untuk mempromosikan kuliner yang dikelola oleh anggota pokdarwis, dilakukan pendampingan dalam pembuatan flyer promosi kuliner tersebut (Gambar 10). Dengan flyer promosi kuliner yang diunggah di media online (Facebook dan Instagram) diharapkan mampu menjadi daya tarik lain bagi pengunjung untuk datang ke tempat wisata Taman Suko. 
Pendampingan dalam pengembangan potensi wisata Taman Suko, juga dilakukan dengan membuat video profil untuk lebih mengenalkan wisata tersebut (Gambar 9). Dengan adanya tambahan tema edukasi tentang sistem akuaponik dan fasilitas swafoto, diharapkan mampu menarik minat pengunjung wisata. Tema edukasi melalui implementasi sistem akuaponik dalam video profil tersebut diharapkan dapat menjadi percontohan bagi bagi masyarakat sekitar, Kelompok Wanita Tani (KWT) dan ibu-ibu PKK yang ada di Desa Sukowilangun untuk mendorong program ketahanan pangan pada skala rumah tangga. Penyebarluasan informasi wisata alam dan edukasi Taman Suko melalui publikasi di media website dengan link https://unmer.ac.id/unmer-malang-turut-kembangkan-potensi-wisataalam-dan-edukasi-tamansuko/ (Gambar 11). Selain itu, video profil Taman Suko juga dipublikasikan secara online di youtube https://youtu.be/0-uXmvrefAU dan di Unmer Channel https://youtu.be/_ Q93YSoErgA (Gambar 12).
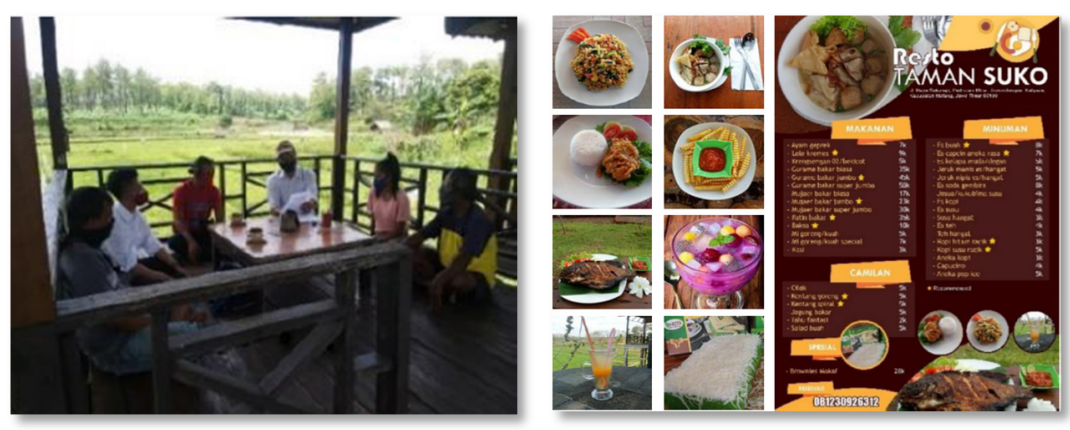

Gambar 9. Pendampingan dalam pembuatan promosi kuliner dan video profil wisata

Gambar 10. Flyer promosi kuliner Resto Taman Suko
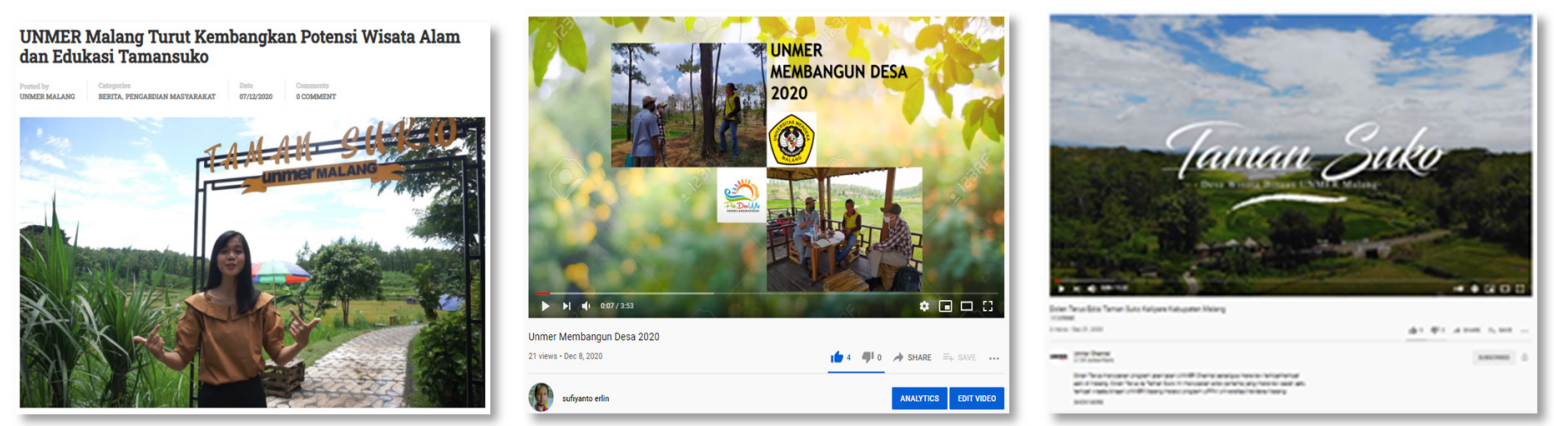

Gambar 11. Publikasi di media website unmer.ac.id

Gambar 12. Publikasi video profil di Youtube dan LPPM Channel

\section{Pembahasan}

Budidaya ikan lele yang dikembangkan oleh mitra menggunakan sistem akuaponik memerlukan waktu 2 bulan. Teknis yang dilakukan adalah pembesaran ikan lele dari umur 1 bulan. Berat awal ikan lele yang dimasukkan ke kolam 18 kg (isi 65 ekor/kg) dengan harga Rp. 20.000,-. Setelah 2 bulan berat 
ABDIMAS: Jurnal Pengabdian Masyarakat Universitas Merdeka Malang Volume 6, No. 4, November 2021: 465-477

ikan lele menjadi 70 kg (isi 15 ekor/kg) dengan harga menjadi Rp. 18.000,-. Adapun rincian perhitungan biaya dan hasil sebagai dalam tabel 1 . Berdasarkan analisa biaya dan hasil pada tabel 1, diperoleh keuntungan selama 2 bulan sebesar Rp. 390.000,- (42,9\%). Untuk hasil panen sayuran relatif sedikit dalam mengkontribusi hasil yang diperoleh secara keseluruhan karena harga jual yang murah dan jumlah lubang tanam terbatas. Hal ini bisa dioptimalkan lagi dengan menambah media tanam tanah di polibag yang diletakkan di sekeliling kolam.

Tabel 1. Analisa biaya dan hasil

\begin{tabular}{|c|c|c|c|c|c|}
\hline Komponen & Jumlah (Kg) & \multicolumn{2}{|c|}{ Harga Per Kg } & \multicolumn{2}{|c|}{ Sub Total } \\
\hline Bibit ikan lele & 18 & $\mathrm{Rp}$ & 20.000 & $\mathrm{Rp}$ & 360.000 \\
\hline Pakan & 45 & $\mathrm{Rp}$ & 11.000 & $\mathrm{Rp}$ & 495.000 \\
\hline Listrik & & & & $\mathrm{Rp}$ & 50.000 \\
\hline \multirow[t]{2}{*}{ Bibit kangkung } & & & & $\mathrm{Rp}$ & 5.000 \\
\hline & & \multicolumn{2}{|c|}{ Total } & $\mathbf{R p}$ & 910.000 \\
\hline Panen ikan lele & 70 & $\mathrm{Rp}$ & 18.000 & $\mathrm{Rp}$ & 1.260 .000 \\
\hline \multirow[t]{4}{*}{ Panen kangkung } & 16 & $\mathrm{Rp}$ & 2.500 & $\mathrm{Rp}$ & 40.000 \\
\hline & & \multicolumn{2}{|c|}{ Total } & $\mathbf{R p}$ & 1.300 .000 \\
\hline & & \multirow{2}{*}{\multicolumn{2}{|c|}{ Saldo }} & $\mathbf{R p}$ & 390.000 \\
\hline & & & & & $42,9 \%$ \\
\hline
\end{tabular}

Untuk dampak publikasi dan video profil di media online belum dapat memberikan perubahan dalam waktu yang singkat. Hal ini tentunya belum dapat diketahui secara langsung setelah informasi tersebut diunggah di media online. Salah satu upaya untuk meningkatkan dampak publikasi di media online adalah dengan memperbanyak sharing di grup komunitas. Potret jumlah pengunjung wisata alam Taman Suko selama periode September s/d November 2020 menunjukkan pada Grafik 1. Secara riil jumlah pengunjung terbanyak adalah pada hari Sabtu dan Minggu. Untuk hari Sabtu sore sampai malam hari, pengunjung didominasi oleh kalangan remaja dan dewasa yang menikmati suasana malam Minggu "Ngopi" di gazebo dan kuliner Resto Taman Suko. Untuk lebih menarik minat pengunjung resto kuliner, pengelola resto menyediakan fasilitas Wi-Fi gratis. Pada Minggu pagi sampai sore, dominasi pengunjungya adalah anak-anak yang menikmati fasilitas kolam renang. Selain itu, untuk pengunjung dewasa dan orang tua dapat menikmati kuliner dan musik karaoke di area gazebo Resto Taman Suko.
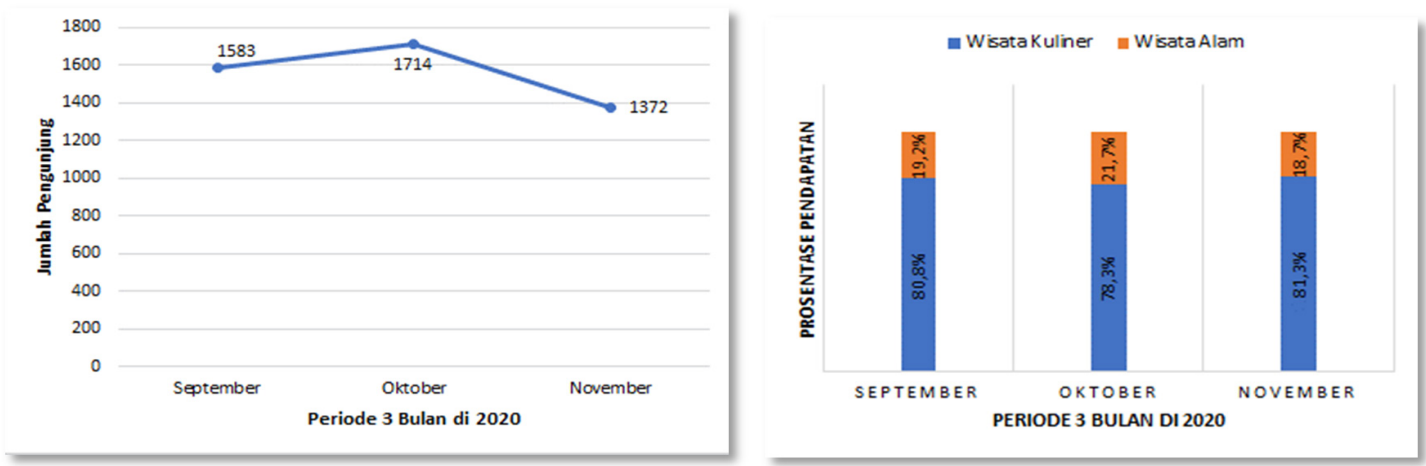

Grafik 1. Jumlah pengunjung periode September s/d November 2020

Grafik 2. Prosentase pendapatan periode September s/d Nopember 2020 


\section{Aquaponic system development as an educational tourism destination in Sukowilangun Village, Malang Regency Sufiyanto Sufiyanto, Mochammad Musafaul Anam, Zaid Dzulkarnain Zubizaretta}

Sumber pendapatan pengelola Wisata Taman Suko berasal dari tiket wisata alam (renang dan parkir) serta hasil penjualan resto kuliner. Berdasar data selama 3 bulan antara September s/d November 2020 (Grafik 2), proporsi pendapatan sebesar 20\% berasal dari wisata alam dan 80\% dari wisata kuliner. Hal ini menunjukkan bahwa keuntungan yang diperoleh dapat dimaksimalkan dengan peningkatan omset dari resto kuliner. Untuk itu, peningkatan kualitas menu yang disediakan merupakan kunci keberhasilan dalam peningkatan omset di resto kuliner.

Analisis selanjutnya perlu dilakukan untuk melihat "Titik Jenuh" dari fasilitas dan daya dukung pengelolaan wisata yang ada sekarang. Pada kondisi tersebut, peningkatan keuntungan dari hasil pengelolaan wisata alam dan kuliner sudah tidak mampu ditingkatkan lagi karena sudah berada pada kondisi maksimal. Oleh karena itu, diperlukan upaya pengembangan lebih lanjut secara fisik dari fasilitas dan luasan area wisata serta daya dukung kuliner yang tersedia. Untuk itu perlu dilakukan perluasan area wisata, penambahan fasilitas wisata dan resto kuliner, serta tenaga kerja. Pengembangan yang dilakukan kedepannya tetap dengan konsep wisata alam dan edukasi melalui pemberdayaan masyarakat secara berkelanjutan untuk meningkatkan perekonomian dan kesejahteraan masyarakat.

\section{SIMPULAN DAN SARAN}

Implementasi sistem akuaponik bagi mitra Pokdarwis Sukowilangun Berseri telah memberikan keuntungan sebagai sumber pendapatan tambahan dalam pengelolaan wisata alam Taman Suko. Hasil panen budidaya ikan air tawar dan tanaman sayuran dari sistem akuaponik telah berhasil memberikan edukasi bagi masyarakat dalam hal pemanfaatan lahan dan sumber air yang terbatas di wilayahnya. Selain itu, implementasi sistem akuaponik juga menjadi tema spesifik bagi Taman Suko sebagai wisata alam edukasi bagi masyarakat. Pendampingan dalam pengembangan potensi wisata Taman Suko dan pemberdayaan masyarakat telah mendorong dan menciptakan peluang usaha mandiri yang produktif dengan cara memanfaatkan sumber daya di sekitarnya. Pemanfaatan media sosial dan internet dalam rangka penyebaran informasi dan promosi wisata secara online melalui video profil wisata dan update konten promosi wisata merupakan hal yang menunjang penyebaraluasan informasi serta jaringan promosi wisata. Dengan demikian, keberadaan wisata alam edukasi Taman Suko dapat lebih dikenal oleh masyarakat luas dan memberikan dampak bagi peningkatan kesejahteraan masyarakat sekitarnya.

Skala implementasi sistem akuaponik perlu ditingkatkan untuk memberikan nilai keuntungan yang lebih besar. Selain itu, pengolahan hasil panen perlu dilakukan untuk memberikan nilai tambah dan disversifikasi produk yang dihasilkan sehingga mampu lebih mengoptimalkan sumber daya yang dimiliki. Untuk itu, dibutuhkan pendampingan secara berkelanjutan dalam pengembangan potensi yang ada melalui pemberdayaan masyarakat yang berbasis komunitas.

\section{UCAPAN TERIMA KASIH}

Ucapan terima kasih penulis sampaikan kepada Universitas Merdeka Malang yang telah memberikan dana pengabdian masyarakat melalui hibah internal Unmer Membangun Desa (UMD) 2020 dengan kontrak no. 076/Kontrak/LPPM/UM/IX/2020, LPPM Unmer Malang yang telah membantu 
ABDIMAS: Jurnal Pengabdian Masyarakat Universitas Merdeka Malang Volume 6, No. 4, November 2021: 465-477

regulasi dan administratif, Pokdarwis Sukowilangun Berseri sebagai Mitra Pengabdian, dan Tim Kreatif Humas Unmer Malang yang telah membantu dalam pembuatan video profil Wisata Alam dan Edukasi Taman Suko.

\section{DAFTAR PUSTAKA}

Anam, M. M. U. (2017). Strategi ikonik wisata untuk memperkenalkan Kota Malang sebagai salah satu destinasi wisata religi. Jurnal Pariwisata Pesona, 2(2), 11. https://doi.org/10.26905/jpp.v2i2.1488

Andrijono, D., \& Sufiyanto, S. (2021). Penyuluhan bagi masyarakat peduli sampah polimer termoplastik Kelurahan Rampal Celaket Kecamatan Klojen Kota Malang. Abdimas: Jurnal Pengabdian Masyarakat Universitas Merdeka Malang, 6(2), 176-185. https://doi.org/10.26905/abdimas.v6i2.5136

Amida, Y. A. (2020). 7 Tanaman sayuran yang cocok untuk sistem akuaponik. HaiBunda. https://www.haibunda.com/moms-life/20201204141839-76-177822/7-tanaman-sayuranyang-cocok-untuk-sistem-akuaponik. diakses 15 Agustus 2021

Bancin, M. H. (2011). Peningkatan partisipasi masyarakat dalam Program Nasional Pemberdayaan Masyarakat (PNPM) mandiri perdesaan (Studi kasus: Bandung Barat). Journal of Regional and City Planning, 22(3), 179-194. https://doi.org/10.5614/jpwk.2011.22.3.2

Budiyanto, H., Haris, M., Setiawan, A. B., Sonalitha, E., \& Iqbal, M. (2019). Teknologi greenhouse hidroganik dengan tenaga listrik mandiri. Prosiding SEMSINA, VII-17. https://ejournal.itn.ac.id/index.php/semsina/article/view/2220

Cahyaningsih, D. S., Suhartono, T., \& Widayati, S. (2021). Menggali potensi ekonomi kreatif sebagai sarana pendukung desa wisata. Abdimas: Jurnal Pengabdian Masyarakat Universitas Merdeka Malang, 6(2), 210-220. https://doi.org/10.26905/abdimas.v6i2.5078

Halim, A., \& Pratamaningtyas, S. (2020). Penerapan aquaponik dan pengembangan budidaya ikan lele pada unit usaha pondok pesantren Kota Malang. Jurnal Layanan Masyarakat (Journal of Public Services), 4(1), 1-7. http://dx.doi.org/10.20473/jlm.v4i1.2020.1-7

Handayani, L. (2018, April). Pemanfaatan lahan sempit dengan sistem budidaya aquaponik. In Prosiding Seminar Nasional Hasil Pengabdian, 1(1), 118-126.

https://e-prosiding.umnaw.ac.id/index.php/pengabdian/article/view/52

Prayogo, P. (2019). Budaya ikan ramah lingkungan dengan sistem akuaponik. Fakultas Perikanan dan Kelautan Universitas Airlangga.

https://fpk.unair.ac.id/budidaya-ikan-ramah-lingkungan-dengan-sistem-akuaponik.

Sant, N. (2017). Kelebihan dan kekurangan sistem aquaponik. Guyub Tani. https://guyubtani.blogspot.com/2017/06/kelebihan-dah-kekurangan-sistem.html.

Sitanggang, L. P. (2019). Pemanfaatan air kolam budidaya ikan sebagai nutrisi pada budidaya tanaman untuk meningkatkan ketahanan pangan di Kabupaten Tapanuli Tengah. Jurnal Penelitian Terapan Perikanan dan Kelautan, 1(2). 1-6.

Sonalitha, E., Widayati, S., \& Setyawan, P. E. (2019, September). Wisata edukasi panorama Jurang Toleh. In Seminar Nasional Sistem Informasi (SENASIF), 3(1), 1837-1842. 
Aquaponic system development as an educational tourism destination in Sukowilangun Village, Malang Regency Sufiyanto Sufiyanto, Mochammad Musafaul Anam, Zaid Dzulkarnain Zubizaretta

Torrido, A. (2013). Pelaksanaan penanggulangan kemiskinan studi Program Nasional Pemberdayaan Masyarakat (PNPM) mandiri. Optimum: Jurnal Ekonomi dan Pembangunan, 3(1), 94-105. https://doi.org/10.12928/optimum.v3i1.7797

Tutuko, P., Widiyaningtyas, T., Sonalitha, E., \& Nurdewanto, B. (2018). Pemberdayaan kelompok rumah pangan lestari dalam budidaya tanaman hidroponik. JAPI (Jurnal Akses Pengabdian Indonesia) 3(1), 7-16. https://doi.org/10.33366/japi.v3i1.843

Widayati, S., Setyawan, P.E., \& Sonalitha, E. (2019). Panorama Jurang Toleh, Jatiguwi, Sumberpucung, Kabupaten Malang, Jawa Timur. Abdimas: Jurnal Pengabdian Masyarakat Universitas Merdeka Malang, 4(2), 12-17. https://doi.org/10.26905/abdimas.v4i2.3804

Yuniarti, S., Sunarjo, S., \& Sedyowati, L. (2020). Budidaya cacing Lumbricus rubellus dengan media limbah jamur sebagai bahan dasar kosmetik dan obat-obatan. Abdimas: Jurnal Pengabdian Masyarakat Universitas Merdeka Malang, 5(2), 93-104.

https://doi.org/10.26905/abdimas.v5i2.4407

Zidni, I., Iskandar, I., Rizal, A., Andriani, Y., \& Ramadan, R. (2019). The effectiveness of aquaponic systems with different types of plants on the water quality of fish culture media. Jurnal Perikanan dan Kelautan, 9(1), 81-94. http://dx.doi.org/10.33512/jpk.v9i1.7076 